\title{
Estimation of convective precipitation: the meteorological radar versus an automatic rain gauge network
}

\author{
M. C. Llasat, T. Rigo, M. Ceperuelo, and A. Barrera \\ Meteorological Hazards Analysis Team (GAMA), Department of Astronomy \& Meteorology, Faculty of Physics, University \\ of Barcelona, Av. Diagonal 647, E-08028 Barcelona, Spain
}

Received: 24 October 2004 - Revised: 18 March 2005 - Accepted: 21 March 2005 - Published: 2 May 2005

\begin{abstract}
The estimation of convective precipitation and its contribution to total precipitation is an important issue both in hydrometeorology and radio links. The greatest part of this kind of precipitation is related with high intensity values that can produce floods and/or damage and disturb radio propagation. This contribution proposes two approaches for the estimation of convective precipitation, using the $\beta$ parameter that is related with the greater or lesser convective character of the precipitation event, and its time and space distribution throughout the entire series of the samples. The first approach was applied to 126 rain gauges of the Automatic System of Hydrologic Information of the Internal Basins of Catalonia (NE Spain). Data are series of 5-min rain rate, for the period 1996-2002, and a long series of 1-min rain rate starting in 1927. Rainfall events were classified according to this parameter. The second approach involved using information obtained by the meteorological radar located near Barcelona. A modified version of the SCIT method for the 3-D analysis and a combination of different methods for the 2-D analysis were applied. Convective rainfall charts and $\beta$ charts were reported. Results obtained by the rain gauge network and by the radar were compared. The application of the $\beta$ parameter to improve the rainfall regionalisation was demonstrated.
\end{abstract}

\section{Introduction}

Main flood events occurring in the West Mediterranean Area are related with high intensity rainfalls, which are usually identified with convective rainfall. However, two questions emerge from this asseveration. The first is related with the fact that not all the precipitation produced by convective systems can be characterised as convective. This problem affects, for instance, the estimation of the rainfall rate using the meteorological radar. The second question refers to the

Correspondence to: M. C. Llasat

(carmell@am.ub.es) morphological and climatic features of this "convective precipitation": thresholds, achieved maximum intensities, spatial and temporal distribution and so on. In this case the answer could be important for the impact on radio links, the improvement of hydrometeorological modelling or the alert system for civil protection.

However, the used methodology to distinguish between convective rainfall and stratiform rainfall is an important issue, though not an easy one (Llasat, 2001). One possibility would be classification of the events into convective or not convective by using conceptual definitions such as the one of the Glossary of Meteorology (Huschke, 1959, p. 545): "Stratiform rainfall as pertaining to clouds of extensive horizontal development in contradiction to "cumuliform".....stratus clouds generally produced little or no precipitation and what little might fall consists of minute particles...". This kind of definition demands an accurate observation of the meteors associated with rainfall as well as their evolution over time. In this research recourse was had to the Jardí rainfall-rate series, located in the region analysed here, and with data since 1927. The advantage is that this instrument recorded instantaneous rainfall and that those people responsible for the Jardí gauge took note of the associated kind of clouds. This availability allowed definition of a parameter useful to characterise the convective/non convective features of an event, on the basis of rainfall rate, called $\beta$ (Llasat and Puigcerver, 1985; Llasat, 2001).

Nowadays, the most useful instrument for identifying convective or non-convective rainfall is the meteorological radar, but there is no universal criterion for identifying a pixel as a convective one or not. This last fact hinders application of the $Z / R$ relationships which depend on the kind of precipitation. Besides this, a convective event can have a strong stratiform component. The original use of the adjective "stratiform" for precipitation is generally attributed to Houghton (1950, 1968), based on the microphysics of the precipitation process, which is closely tied in with the character and magnitude of in-cloud vertical motions. In Houze (1993) the definition of stratiform precipitation is the vertical air 


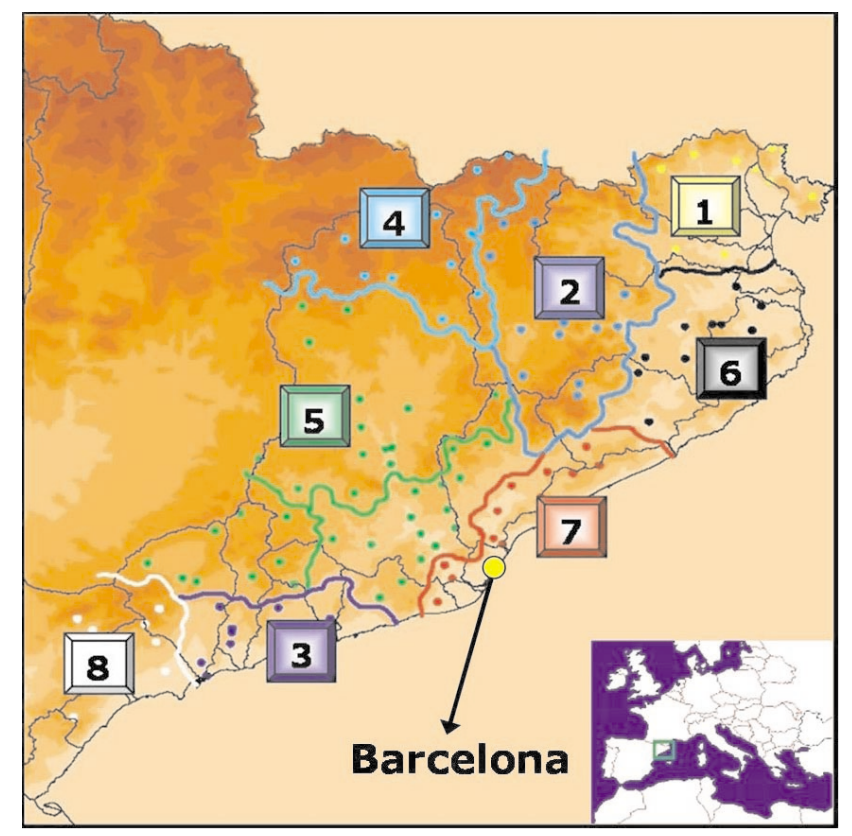

Fig. 1. Pluviometric regionalisation of Catalonia on the basis of the monthly rainfall, daily rainfall and monthly $\beta$ parameter.

velocity that satisfies the condition "vertical velocity inferior to the terminal fall velocity of ice crystals and snow". Together with this feature, and using 3-D radar imagery, the "bright band" near the melting level is a signature that helps to distinguish convective mode from stratiform mode. The same author (Houze, 1997) has published a paper devoted to the paradox of stratiform precipitation in regions of convection. Steiner et al. (1995) propose two methods for distinguishing between stratiform and convective precipitation in the radar echo patterns that are commonly used nowadays (mainly the operative method, known as the Steiner-HouzeYuter method). Biggerstaff and Listemaa (2000) have published a paper proposing some improvements to this method, used as current operational version in the Tropical Rainfall Measuring Mission. But, in spite of all those works and others not mentioned here, no common agreement exists about the problem inherent in the observed transition from convective to stratiform structure, mainly in convective systems. In the particular case of Catalonia we only have radar data since 1994, and a continuous series since 1996.

The scope of this paper is the comparison between the identification of convective precipitation by using both sources of data (meteorological radar and a raingauge network), that will allow the soundness of the criteria proposed to be analysed. The proposal of a classification on the basis of convective features and their application to a rainfall regionalisation is the second objective of this paper.

The paper starts with characterisation of convective events on the basis of the instantaneous rainfall rate series of Barcelona (1927-1981). Then, the potential applications of this methodology are analysed using the 5-min rainfall series of an automatic rainfall network located in Catalonia (1996-
2002). Finally, the appropriateness of $\beta$ parameter and its application to characterise the physical features of convective precipitation is analysed on the basis of radar and lightning data.

\section{Estimation of convective precipitation from a long rainfall rate series: the case of Barcelona}

The analysis was undertaken for Catalonia (NE Spain). This region has an area of $35000 \mathrm{~km}^{2}$ and is characterised by a strong orography that has a determinant role in the development and convection triggering. Main orographic features are a mountain range (Littoral) parallel to the coast with some peaks exceeding $500 \mathrm{~m}$, a second range (Prelittoral) with peaks exceeding $1000 \mathrm{~m}$ and the Pyrenees which exceed $3000 \mathrm{~m}$. The Jardí pluviograph is installed near Barcelona, in the Littoral Range, at an altitude of $414 \mathrm{~m}$ a.s.l, and at a distance of $7.5 \mathrm{~km}$ from the sea (Fig. 1). This is one of the oldest rain gauges in the world with instantaneous rainfall rate data (Jardí, 1921; Puigcerver et al., 1986). In this case, and after digitising the rainfall charts, the data available are series of 1-min and 5-min rainfall intensities for the period 1927 1981, following which the series is interrupted due to some homogeneity problems.

Some previous studies (Llasat and Puigcerver, 1997) show that the hypothesis used to consider that an episode is convective when 1-min rainfall rate is above $50 \mathrm{~mm} / \mathrm{h}$ is not unreasonable, all the more so if it is borne in mind that we are interested in high intensities. The methodology proposed herein for resolving that objective consists in taking as a point of departure a mean intensity threshold within a given time interval, and in the introduction of the parameter $\beta$ which takes into account the ratio between rainfall that exceeds that threshold and total rainfall in an episode (Llasat, 2001).

$\beta_{L, \Delta T}=\frac{\sum_{i=1}^{N} I(t i, t i+\Delta T) \theta(I-L)}{\sum_{i=1}^{N} I(t i, t i+\Delta T)}$

in which, $\Delta T$ is the time-interval of accumulation of the precipitation, expressed in minutes; $N$ is the total number of $\Delta T$ integration steps into which the episode is subdivided; $I\left(t_{i}\right.$, $\left.t_{i}+\Delta T\right)$ is the precipitation measured between $t_{i}$ and $t_{i}+\Delta T$ divided by $\Delta t$, that is, the mean intensity in the said interval expressed in $\mathrm{mm} / \mathrm{min}$ or $\mathrm{mm} / \mathrm{h} ; \theta(I-L)$ is the Heaviside function defined as:

$\theta(I-L)=\left\{\begin{array}{ll}1 & \text { if } I \geq L \\ 0 & \text { if } I<L\end{array}\right.$.

where $L$ is the intensity threshold and depends on the $\Delta T$ integration steps. When 1-min precipitation series is considered the selected threshold for $L$ is $50 \mathrm{~mm} / \mathrm{h}$, but for 5 -min precipitation series, it is possible to demonstrate that the $L$ value is equal to $35 \mathrm{~mm} / \mathrm{h}$ in this case (Llasat, 2001). 
Table 1. Distribution of convective events for the representative station of each IBC subregion. Data in brackets refer to the ratio between convective events $(\beta>0)$ and total events for each station.

\begin{tabular}{|c|c|c|c|c|c|c|c|c|}
\hline & Group1 & Group2 & Group3 & Group4 & Group5 & Group6 & Group7 & Group8 \\
\hline Representative station number & $28(5.3 \%)$ & $55(5.5 \%)$ & $203(7.0 \%)$ & $150(5.1 \%)$ & $170(4.5 \%)$ & $86(5.0 \%)$ & $128(6.7 \%)$ & $235(5.4 \%)$ \\
\hline Representative $\beta$ threshold: $\beta<0.3$ & $18.8 \%$ & $25.8 \%$ & $32.7 \%$ & $24.6 \%$ & $28.6 \%$ & $35.4 \%$ & $29.5 \%$ & $34.1 \%$ \\
\hline Representative $\beta$ threshold: $0.3<\beta<0.8$ & $68.7 \%$ & $62.9 \%$ & $65.4 \%$ & $67.2 \%$ & $66.7 \%$ & $54.2 \%$ & $59.0 \%$ & $59.1 \%$ \\
\hline Representative $\beta$ threshold: $\beta>0.8$ & $12.5 \%$ & $11.3 \%$ & $1.9 \%$ & $8.2 \%$ & $4.8 \%$ & $10.4 \%$ & $11.5 \%$ & $6.8 \%$ \\
\hline
\end{tabular}

It is thus possible to draw up a classification of the rainfall events in the light of their greater or lesser convective character:

0. $\beta=0 \Rightarrow$ non-convective

1. $0<\beta<0.3 \Rightarrow$ slightly convective

2. $0.3<\beta<0.8 \Rightarrow$ moderately convective

3. $0.8<\beta<1.0 \Rightarrow$ strongly convective

The application to the 5-minute series of Jardí data shows that for $1.5 \%$ of the mean annual time for which it rains, the precipitation presents a mean 5-minute intensity exceeding $35 \mathrm{~mm} / \mathrm{h}$, and it produces $18.2 \%$ of the total annual precipitation. If we impose as condition to separate two rainfall episodes that the lapse time without precipitation is $1 \mathrm{~h}, 8 \%$ of the rainfall episodes are convective $(\beta>0$, because during a greater or lesser time over the event, the intensity of $35 \mathrm{~mm} / \mathrm{h}$ is reached) and provide $36.5 \%$ of the total annual precipitation. The largest number of events occurs in autumn, with mean seasonal value of 12 episodes; nevertheless, the largest percentage of the total occurs in August, with just over $18 \%$, providing $64 \%$ of the total monthly precipitation. In March, the percentage of events falls to $1.8 \%$ (only $13 \%$ of the precipitation is convective). With the exception of autumn, these are episodes with a duration of less than 4 hours, and they are shorter the greater the intensity reached.

To go into further detail, $3.8 \%$ belong to slightly convective episodes, $2.9 \%$ to moderately convective episodes and $1.3 \%$ to strongly convective episodes. It can be noted that the strongly convective episodes last less than $1 \mathrm{~h}$, while the slightly convective ones last for longer than $1 \mathrm{~h}$. The catastrophic rainfall episodes and floods are usually linked with moderately convective episodes that can last between a few hours and a few days.

\section{Application to an automatic rainfall network: The case of the Internal Basins of Catalonia}

Once the $\beta$ parameter has been analysed for an individual long series, the next step is to apply it to an extensive region. With this aim, the SAIH (Automatic System of Hydrological Information) of the Internal Basins of Catalonia (IBC) has been considered. It is composed of 126 automatic rain gauges that cover an area of $16000 \mathrm{~km}^{2}$, with available data since 1996. Rainfall values are recorded every $5 \mathrm{~min}$ and sent by radio to the control centre, located in Barcelona.
When the 126 rain gauges are considered for the entire period, the distribution of convective episodes per rain gauge lies between $3 \%$ and $9 \%$ of the total events. This range of values depends on the zone of Catalonia considered. The distribution between the different types of episodes per rain gauge shows that between $0.2 \%$ and $3 \%$ of the total episodes are slightly convective (1\%-18\% of annual precipitation), while the moderate convective ones have values between $1.5 \%$ and $6 \%(6 \%-30 \%$ of annual precipitation). Although the strongly convective events (type 3) account for only $0.5 \%$ of total episodes in some regions, they can give rise to more than $5 \%$ of the total rainfall in some regions.

Following the previous comments it should be borne in mind that convective rainfall features, including from a climatic point of view, can be very different from one place to another. Thus, one interesting application of $\beta$ is the improvement of rainfall regionalisation taking account of its convective features (Ceperuelo, 2004). This fact is important in a region characterised by some zones with torrential rainfalls (i.e. daily rainfall values above $200 \mathrm{~mm}$, sometimes recorded in less than $6 \mathrm{~h}$ ), other zones with low yearly precipitation but produced by short and heavy rainfall events, and yet other zones characterised by similar accumulated precipitation but usually produced by longer slightly convective events or stratiform ones. The regionalisation was undertaken by applying the Principal Component Analysis (PCA) to monthly and daily rainfall, as well as to $\beta$ monthly values, followed by a cluster analysis (Ceperuelo and Llasat, 2004, 2005). This new proposal of regionalisation (Fig. 1) has the advantage of considering the convective climatic features of the rainfall. This fact is important not only for the better design of Intensity Duration Frequency (IDF) curves for the different sub-regions, but also for local rainfall forecasting and warnings (Llasat, 2001). We might note that the regions with the greatest contribution of convective precipitation have values above $30 \%$ of the total annual rainfall; i.e. more than $150 \mathrm{~mm} /$ year are associated with convective events with moderate and high intensity. Table 1 shows the distribution of convective events in each subregion. This fact constitutes a serious problem because more than $65 \%$ of the population in Catalonia lives in such sub-regions and flood emergency management is complicated thereby. As a consequence, considerable damage is produced by those heavy rainfall episodes. 


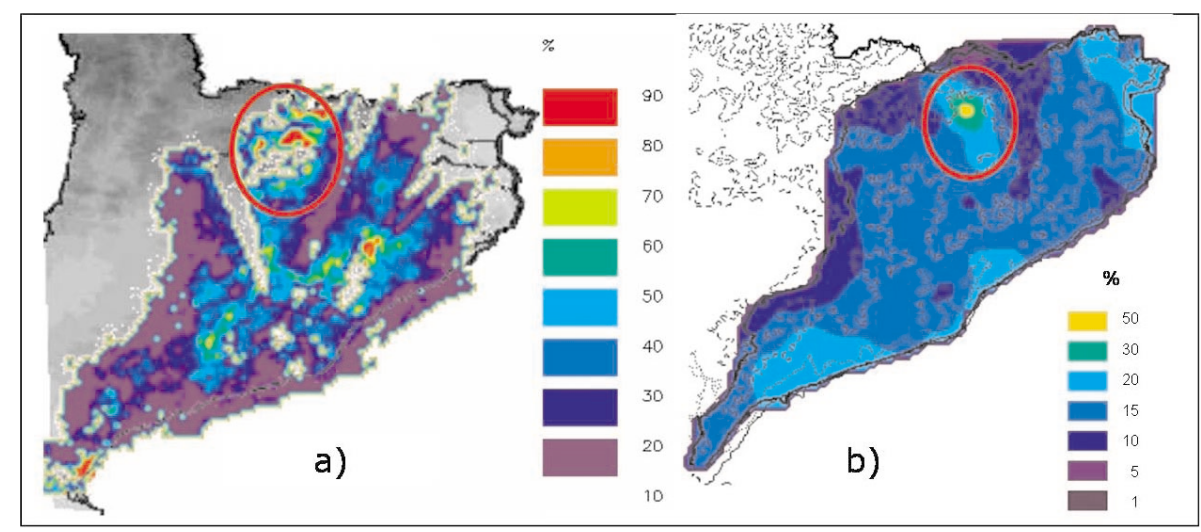

Fig. 2. Percentage of convective rainfall ( $\beta$ values) versus total rainfall recorded during the heavy rainfall events (1996-2000): (a) total convective rainfall obtained by the meteorological radar; (b) total $\beta$ charts obtained by rain gauge data. Both cases (radar and rain gauges) show maximum convective precipitation over the Pyrenees.

Finally, in order to characterise the rainfall events taking into account the $\beta$ parameter, all those cases with maximum daily rainfall in one station above $35 \mathrm{~mm}$ were considered. Although this threshold might be considered low, it coincides with the lesser quantity that has to be recorded in $1 \mathrm{~h}$ by one pluviograph in order to issue a warning of heavy rainfalls on the basis of the alert system of the Spanish National Weather Service. A total of 226 events were identified and 35 of them produced floods or inundations. In this case events are considered from a regional point of view and two events are different when the lapse of time without rainfall in the IBC is above $3 \mathrm{~h}$. With these considerations in mind, $92 \%$ of those events have a $\beta$ value greater than 0 , and a distribution of $13 \%$ type $1,47 \%$ type $2,40 \%$ type 3 . Then, the next step is to select a sample of those events to be analysed in conjunction with the meteorological radar and to check the soundness of the $\beta$ parameter.

\section{Estimation from the meteorological radar: the case of Catalonia}

The C-band radar of the Instituto Nacional de Meteorología (Spanish Weather Service, INM) is located at $612 \mathrm{~m}$ a.s.l to the southwest of Barcelona city. Radar volumes on Normal mode are generated every $10 \mathrm{~min}$. The range of the images is $240 \mathrm{~km}$ and the size of the pixels is $2 \times 2 \mathrm{~km}^{2}$. The first elevation of the bin is $0.5^{\circ}$, and the scan included 20 elevations, for which are obtained 12 CAPPIs by means of interpolation procedures. The images used in the present paper are the complete radar volume, which includes the lowest PPI scanned, and 12 CAPPIs (with altitudes between 0.8 and $15.8 \mathrm{~km})$.

The procedure applied to deal with the present study is based on the application of specific algorithms that allow a distinction to be made between pixels associated with convective or stratiform precipitation. With this aim, only the PPI or the lowest CAPPI were used. The complete volume and the other CAPPIs were used for applying the 3-D algo- rithm and identifying the convective cells, in order to find out the complete physical structure of the cloud and take account of the possible effect of the bright band. Both procedures, 2$\mathrm{D}$ and 3-D, were adapted and assimilated to the region, starting from works such as Steiner et al. (1995), Biggerstaf and Listemaa (2000), or Johnson et al. (1998). However, taking into account the objective of this paper, only the 2-D procedure will be commented upon here.

The adapted 2-D process (Rigo, 2004; Rigo and Llasat, 2004) is based on the algorithm of Johnson et al. (1998) to identify convective pixels. It considers three requirements that are independent one from another. One pixel is considered "convective" if it verifies at least one of them. Firstly, a reflectivity threshold was applied in order to obtain pixels that could be considered as "convective" with a high confidence. This first point is associated with the fact that, generally, convective rain rates are more intense than stratiform values (Llasat, 2001). Although Johnson et al. (1998) proposes a value above $40 \mathrm{dBz}$, comparison with the $\beta$ chart obtained from the raingauges will allow a more specific value to be found. In order to avoid false echoes, we propose a minimum size for the "convective" pixel, with a radius of $10 \mathrm{~km}$. Secondly, a pixel that does not exceed the "convective" threshold was labelled as "convective" if the difference between its value and a mean value of its background exceeds a considered function, which depends on the background reflectivity and the radar characteristics. This second point considers the strong gradient observed in areas where convective precipitation is produced. The third requirement considers that if there are some "convective" pixels adjacent to the analysed pixel, the latter could be considered as "convective". This requirement was applied in order to consider as convective those pixels located on the borderline of the convective area that do not fulfil the previous criteria but are part of the convective system. Once the three requirements had been applied to all the pixels, those that did not verify any of them but that had a reflectivity above $18 \mathrm{dBz}$ were classified as "stratiform". The last point to validate the appropriateness 


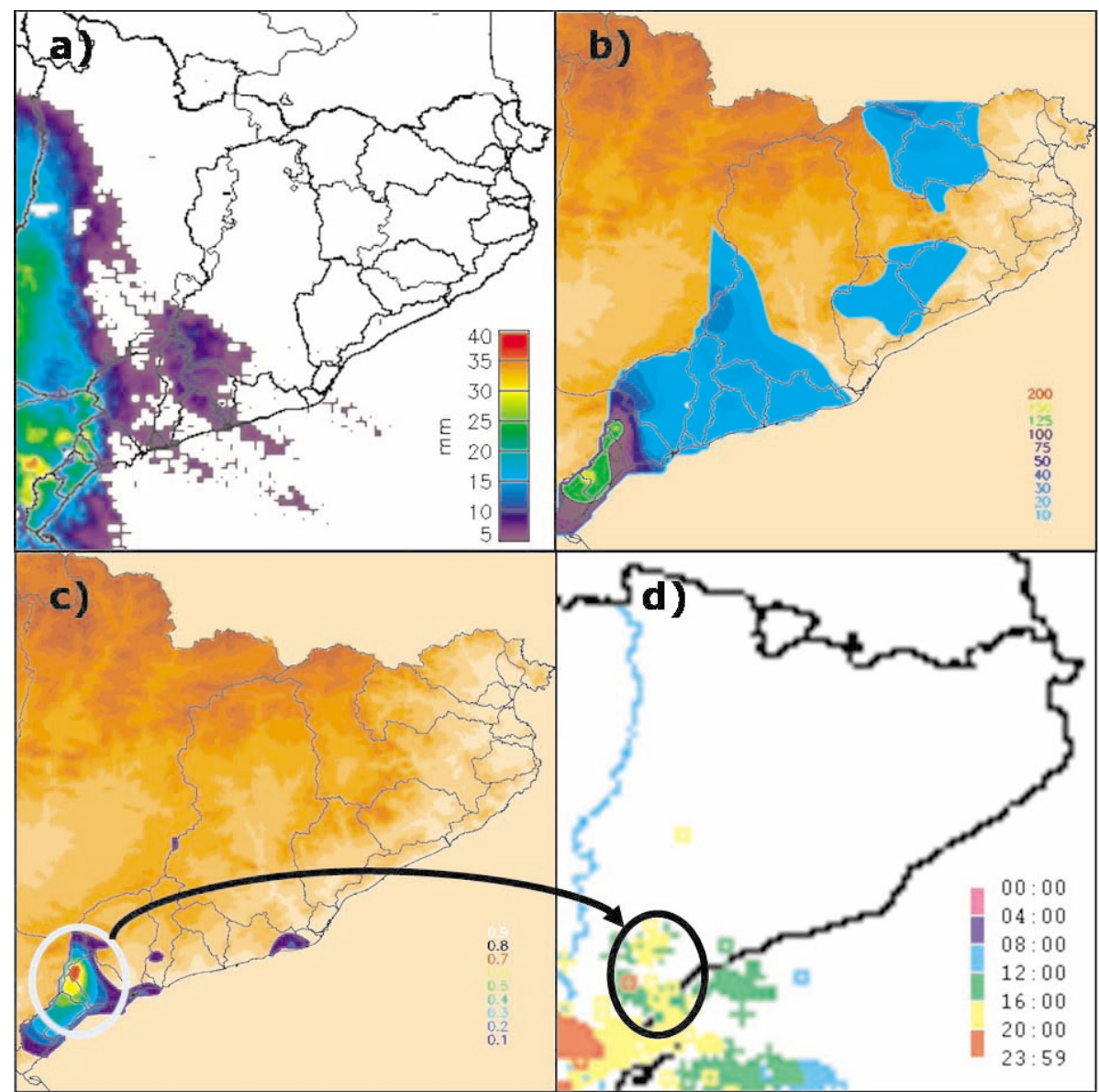

Fig. 3. Comparison between the rainfall fields obtained by the meteorological radar (a) and rain gauge network (b), the $\beta$ chart obtained by rain gauge data (c) and the lightning distribution (d). Accumulated values from 22:00 UTC, 21 October 2002 to 22:00 UTC, 22 October 2002.

of the selected convective region uses the entire radar volume and considers the vertical gradient of the reflectivity, following the proposal of Biggerstaf and Listemaa (2000). The objective is to re-classify those pixels associated with the bright band as stratiform ones.

Once the 2-D algorithm has been applied, it is possible to calculate the value of the $\beta$ parameter for each pixel, using different $Z / R$ relations depending on the convective or stratiform character of the precipitation (Rigo and Llasat, 2002):

Convective (NEXRAD):

$Z=200 \cdot R^{1.4}$

Stratiform (Marshall and Palmer, 1948):

$Z=200 \cdot R^{1.6}$

Once the convective precipitation and the total precipitation had been obtained from the weather radar, it would then be possible to calculate the $\beta$ value for each pixel. From the comparison of the different charts, from radar and rain gauges and testing different reflectivity thresholds, it proved possible to determine that the most common reflectivity threshold for convective rainfall in Catalonia lies close to $43 \mathrm{dBz}$. Then, all those pixels that would be identified as convective, following the criteria proposed in Rigo and Llasat (2004), would have $\beta$ values other than zero.

The results obtained for the heavy rainfall events analysed for the period 1996-2000 has helped to identify the areas where the convective precipitation presents a maximum frequency in the region. The comparison of the $\beta$ chart obtained for the entire period by means of the rain gauge network and the percentage of convective rainfall calculated for the radar images shows a strong qualitative agreement (Fig. 2), with a maximum in the Pyrenees region. The main differences between the two maps are mainly due to the different temporal and spatial intervals considered by the two methods: a kriging interpolation was applied to 5-min raingauge data, meanwhile an average 10-min precipitation for each pixel of $2 \mathrm{~km} \times 2 \mathrm{~km}$ is considered when radar data are used. Besides this, other effects such as topography have to be considered because they can affect the radar imagery. 


\section{Conclusions}

The application to the 5-minute series of Jardí data shows that $8 \%$ of the rainfall episodes are convective $(\beta>0)$ and provide $36.5 \%$ of the total annual precipitation.

To go into further detail, $3.8 \%$ belong to slightly convective episodes, $2.9 \%$ to moderately convective episodes and $1.3 \%$ to strongly convective episodes.

When the 126 rain gauges are considered for the period as a whole, the distribution of convective episodes per rain gauge lies between 3\% and 9\% of the total events. The distribution between the different types of episodes per rain gauge shows that between $0.2 \%$ and $3 \%$ of the total episodes are slightly convective (1\%-18\% of annual precipitation), while the moderately convective ones have values between $1.5 \%$ and $6 \%(6 \%-30 \%$ of annual precipitation). Strongly convective events can give rise to more than $5 \%$ of the total rainfall in some regions. Particularly, a total of 226 events with more than $35 \mathrm{~mm} / 24 \mathrm{~h}$ were identified for the period 1996 2002 , and 35 of them produced floods or inundations. $92 \%$ of those events have a $\beta$ value greater than 0 , and a distribution of $13 \%$ for type $1,47 \%$ for type 2 and $40 \%$ for type 3.

Then, taking into account that convective rainfall features can vary greatly from one place to another in the analysed region, a rainfall regionalisation of Catalonia including them has been proposed. The regionalisation was undertaken by applying the Principal Component Analysis to monthly and daily rainfall, as well as to $\beta$ monthly values, followed by a cluster analysis. Eight sub-regions were defined and characterised.

From a comparison of the different charts, from radar and rain gauges and by testing different reflectivity thresholds, it proved possible to determine that the most common reflectivity threshold for convective rainfall in Catalonia is close to $43 \mathrm{dBz}$.

The use of remote sensing proved necessary for integrating both points of view: the one that considers the precipitation structure at the surface, and the other one that considers the structure of the cloud system. Firstly, the use of radar allowed verification of the areas with convective precipitation $(\beta>0)$ and the zones with maximum $\beta$ values. In the same way, lightning data played an important role for finding the relationship between rain rate and the presence of severe phenomena: in general, a high concordance between elevated values of the $\beta$ parameter and important densities of strokes was observed (Fig. 3).

The $\beta$ parameter was revealed as a good indicator of the convective activity, both from a meteorological and climatological point of view. It can be used for substituting radar information where not available, or for completing it, in order to identify convective rainfall. The $\beta$ parameter improves the regionalisation procedure on the basis of rainfall features, which can help the prevention of heavy rainfall region by region.
Acknowledgements. The authors thank the MONEGRO (REN2003-09617-C02-02) Spanish project, the AMPHORE (Interreg IIIB MEDOCC 2003-03-4.3-I-079) and the HYDROPTIMET (Interreg IIIB MEDOCC 2002-01-4.3-E-027) European projects for enabling the drawing up and presentation of this contribution. Our thanks to the A. Catalana de l'Aigua of the Generalitat de Catalunya and to the Instituto Nacional de Meteorología for the rain gauge and radar data.

Edited by: L. Ferraris

Reviewed by: anonymous referees

\section{References}

Biggerstaf, M. and Listemaa, S. A.: An improved scheme for convective/stratiform echo classification using radar reflectivity, Journal of Applied Meteorology, 39, 2129-2150, 2000.

Ceperuelo, M.: Diseño de una herramienta para el tratamiento de la lluvia 5-minutal en las Cuencas Internas de Catalunya, Aplicación al estudio de la distribución espacial de la precipitación convectiva, Bachelor on Meteorology, Internal Publication, 2004.

Ceperuelo, M. and Llasat, M. C.: La Precipitación Convectiva en las Cuencas Internas de Catalunya, Revista del Aficionado a la Meteorología, 23, http://www.meteored.com/ram/numero23/indice. asp, 2004.

Ceperuelo, M. and Llasat, M. C.: Regionalización Pluviométrica de las Cuencas Internas de Cataluña en función de la precipitación convectiva, Revista del Aficionado a la Meteorología, 27, http: //www.meteored.com/ram/numero27/indice.asp, 2005.

Houghton, H. G.: A preliminary quantitative analysis of precipitation mechanisms, Journal of Meteorology, 7, 363-369, 1950

Houghton, H. G.: On precipitation mechanisms and their artificial modification, Journal Applied Meteorological, 7, 851-859, 1968.

Houze Jr., R. A..: Cloud Dynamics, Academic Press, 573 pp, 1993.

Houze Jr., R. A.: Stratiform precipitation in regions of convection: A meteorological paradox?, Bulletin of the American Meteorological Society, 78, nr. 10, 2179-2196, 1997.

Huschke, R. E.: Glossary of Meteorology, American Meteorological Society, 638 pp, 1959.

Jardí, R.: Un pluviògraf d'intensitats, Notes d'Estudi del Servei Meteorològic de Catalunya, I, 3-10, 1921.

Johnson, J. T., MacKeen, P. L., Witt, A., Mitchell, E. D., Stumpf, G. J., Eilts, M. D. and Thomas, K. W.: The Storm Cell Identification and Tracking (SCIT) algorithm: An enhanced WSR-88D algorithm, Weather Forecasting, 13, 263-276, 1998.

Llasat, M. C.: An objective classification of rainfall events on the basis of their convective features, Application to rainfall intensity in the North-East of Spain, International Journal of Climatology, 21, 1385-1400, 2001

Llasat, M. C. and Puigcerver, M.: Un intento de aplicación a la Península Ibérica de un modelo empírico de precipitación, Revista de Geofísica, 41, 135-144, 1985.

Llasat, M. C. and Puigcerver, M.: Total rainfall and convective rainfall in Catalonia, Spain, International Journal of Climatology, 17, 1683-1695, 1997.

Marshall, J. S. and Palmer, W. M. K.: The distribution of raindrops with size, J. Meteor., 5, 165-166, 1948

Puigcerver, M., Alonso, S., Lorente, J., Llasat, M. C., Redaño, A., Burgueño, A. and Vilar, E.: Preliminary aspects of rainfall rates 
in the North East of Spain, Theoretical Applied Climatology, 37, 97-109, 1986.

Rigo, T.: Estudio de sistemas convectivos mesoescalares en la zona mediterránea occidental mediante el uso del radar meteorológico, $\mathrm{PhD}$ thesis, University of Barcelona, Internal publication, 2004.

Rigo, T. and Llasat, M. C.: Analysis of convection in events with high amounts of precipitation using the meteorological RADAR, in: Proceedings of the 4th EGS Plinius Conference on Mediterranean Storms, edited by: Jansà, A. and Romero, R., Mallorca, Spain, 2-4 October (CD-ROM), Session 1, no. 36, 2002.
Rigo, T. and Llasat, M. C.: A methodology of convective structures using meteorological radar: Application to heavy rainfall events on the Mediterranean coast of the Iberian Peninsula, Nat. Haz. Earth Sys. Sci., 4, 59-68, 2004,

SRef-ID: 1684-9981/nhess/2004-4-59.

Steiner, M., Houze, R. A., and Yuter, S. E.: Climatological characterization of three-dimensional storm structure from operational radar and rain gauge data, Journal of Applied Meteorology, 34, 1978-2007, 1995. 